\title{
Caricatures and Prop Oriented MaKe-Believe
}

\author{
ELISA CALDAROLA \\ Department of Philosophy, Sociology, Education Science, and Applied Psychology \\ University of Padova
}

MATTEO PLEBANI

Department of Philosophy and Anthropology

University of Santiago de Compostela

\begin{abstract}
A caricature can reveal an aspect of its subject that a more faithful representation would fail to render: by depicting a slow and clumsy person as a monkey one can point out such qualities of the depicted subject, and by depicting a person with quite big ears as a person with enormous ears one can point out that the depicted person has rather big ears. How can a form of representation that is by definition inaccurate be so representationally powerful? Figurative language raises a similar puzzle. Metaphors, taken at face value, are usually false: men are not wolves. The same goes for hyperbolic talk: Putnam did not change his position one billion times in his career. Still, figurative language is expressively powerful: by saying that human beings are wolves or that Putnam changed his position one billion times in his career one conveys, in a very vivid way, some true information about the world (something concerning the facts that human beings are cruel and that Putnam frequently changed opinion). Kendall Walton (1993) provides an elegant explanation of the expressive utility of figurative language by linking metaphor and prop oriented make-believe. We explore the hypothesis that the theory of prop oriented make-believe can also explain the representational efficacy of caricatures.
\end{abstract}

\footnotetext{
Caricatures pose a puzzle. On the one hand, by their nature, they misrepresent their subjects to some extent. On the other hand, they seem to be effective representational aids: a caricature can sometimes reveal an aspect of its subject that a more faithful representation would fail to render. How is this
}

Contact: Elisa Caldarola <elisa.caldarola@unipd.it>; Matteo Plebani <plebani.matteo@gmail.com> 
possible? How can a form of representation that is by definition inaccurate be so representationally powerful?

This paper brings together two ideas. First, the puzzle raised by caricatures somehow resembles the puzzle raised by figurative language. Metaphors, taken at face value, are usually false: men are not wolves. The same goes for hyperbolic talk: Putnam did not change his position one billion times in his career. Still, figurative language is expressively powerful: by saying that human beings are wolves or that Putnam changed his position one billion times in his career one conveys, in a very vivid way, some true information about the world (something concerning the facts that human beings are cruel and that Putnam frequently changed opinion). ${ }^{1}$

Our second idea stems from the observation that Kendall Walton's theory of make-believe $(1973 ; 1990 ; 1993)$ is at the same time an account of the phenomenon of depiction and other forms of representation and an account of figurative language, especially metaphor, as prop oriented make-believe. This suggests the possibility of treating caricatures in analogy with figurative language. And this is the suggestion we are going to explore.

We proceed as follows: in Section 1 we sum up the kernel of Walton's theory of make-believe and introduce his distinction between content oriented and prop oriented make-believe; in Section 2 we argue that Walton's account applies to depicted metaphors; in Section 3 we argue that some caricatures are a kind of depicted metaphors, whose workings are illuminated by the make-believe theory; in Section 4 we argue that the make-believe theory also explains how caricatures that are like hyperboles work; Section 5 concludes.

I.

What is a game of make-believe? In a game of make-believe we pretend that something is the case. Games are rule-governed activities, and the rules governing games of make-believe are called 'principles of generation'. A principle of generation specifies what is to be imagined to be the case (i.e., the contents of the game of make-believe) as a function of what really is the case (i.e., the props of the game of make-believe). The general scheme can be expressed as follows:

G iff according to the fiction $F$

1. Both Nelson Goodman (1968) and Stephanie Ross (1974) have noticed the resemblance between caricatures and metaphors, although they haven't elaborated much on this point. Noël Carroll (2003) has put forward an account of visual metaphors which-it seems to us-could be applied to caricatures. 
where G stands for what is really the case, and F stands for what is fictionally the case. For instance, here is a game of make-believe governed by two principles of generation (see Liggins 2014: 603):

(PGI) $x$ is wearing a funny hat iff according to the fiction $x$ is the King of France

$\left(\mathrm{PG}_{2}\right) \mathrm{x}$ is lying on the floor iff according to the fiction $\mathrm{x}$ is injured

$\left(P_{1}+P_{2}\right)$ The man with the funny hat is lying on the floor iff according to the fiction the King of France is injured.

Principles of generation link what is the case (the props) with what is to be imagined to be the case (the contents). Normally, the point of a game of make believe is to engage in certain imaginative activities. When children pretend that pieces of mud are pies or when we pretend that what we read in a novel is really the case, the focus of our attention is on the fictional truths generated by the principles of generation. Participants in a game of make-believe typically adapt their behavior to what is to be imagined to be the case, i.e., the game's content. This is what happens in what Walton (1990) calls 'content oriented games of make-believe'.

Principles of generation, however, are a two-way road. This is particularly clear in our formulation, in which they are bi-conditionals:

(PG) G iff according to the fiction F.

PG demands participants to the game of make-believe to imagine that $\mathrm{F}$, on condition that G. But PG also tells us that $\mathrm{G}$ must be really the case, if $\mathrm{F}$ is to be imagined to be the case. This shows how knowledge of the game contents delivers information about the real world, i.e., about the props. In our toy example, by knowing that it is fictionally true that the King of France is injured we know that is true simpliciter that the man with the funny hat is lying on the floor.

The point of pretending that $\mathrm{F}$ as a move in a game of make-believe regulated by PG might in principle be to draw our attention to $G$, the real world fact that makes $\mathrm{F}$ pretense-worthy. In particular, if a principle of generation takes the form ' $p$ iff according to the pretense $q$ ' then someone who says that $q$ within the pretense can communicate that it is the case that $\mathrm{p}$ in the real world (see Liggins 2014: 603). When games of make-believe are used in this way, we are dealing with what Walton (1993) calls 'prop oriented games of make-believe'; such games might be also called world oriented (see Yablo 2005), given that the 
props belong to the real (as opposed to the fictional) world. ${ }^{2}$ Walton gives some examples of prop oriented games of make-believe:

Where in Italy is the town of Crotone? I ask. You explain that it is on the arch of the Italian boot. 'See that thundercloud over there - the big, angry face near the horizon,' you say; 'it is headed this way.' ... We speak of the saddle of a mountain and the shoulder of a highway.

All of these cases are linked to make-believe. We think of Italy and the thundercloud as something like pictures. Italy (or a map of Italy) depicts a boot. The cloud is a prop which makes it fictional that there is an angry face. . . . The saddle of a mountain is, fictionally, a horse's saddle. But our interest, in these instances, is not in the make-believe itself, and it is not for the sake of games of make-believe that we regard these things as props. ... [The make-believe] is useful for articulating, remembering, and communicating facts about the props - about the geography of Italy, or the identity of the storm cloud ... or mountain topography. It is by thinking of Italy or the thundercloud . . . as potential if not actual props that I understand where Crotone is, which cloud is the one being talked about. (1993: 40-41)

'Crotone is on the arch of the Italian boot' likens the Italian peninsula to a boot. This metaphorical statement introduces a game of prop oriented makebelieve because it engages us in a game of make-believe where we pretend that the Italian peninsula, with its peculiar geography (the prop), is a boot (that Crotone is on the arch of the Italian boot is then the content of the game) and, in virtue of this, it conveys useful information as to where in Italy Crotone is located. While engaging in this game we are not interested in imagining a story where we pretend that the Italian peninsula is a boot (content orientation), but we are interested in finding out a fact about the real world, i.e., where exactly Crotone is located in the Italian peninsula (prop orientation).

\section{2.}

When discussing prop oriented games of make-believe Walton explains that his "general idea is this: the metaphorical statement ['Crotone is on the arch of the

2. In reply to a question raised by a referee, it might be worth noticing that there is no way to tell whether a game of make-believe is prop or content oriented by just looking at its principles of generation. The logical structure of the principles is the same in both cases (a bi-conditional). Rather, the difference between prop and content oriented games of make-believe lies in the way the principles of generation are used by those who play the relevant game of make-believe. 


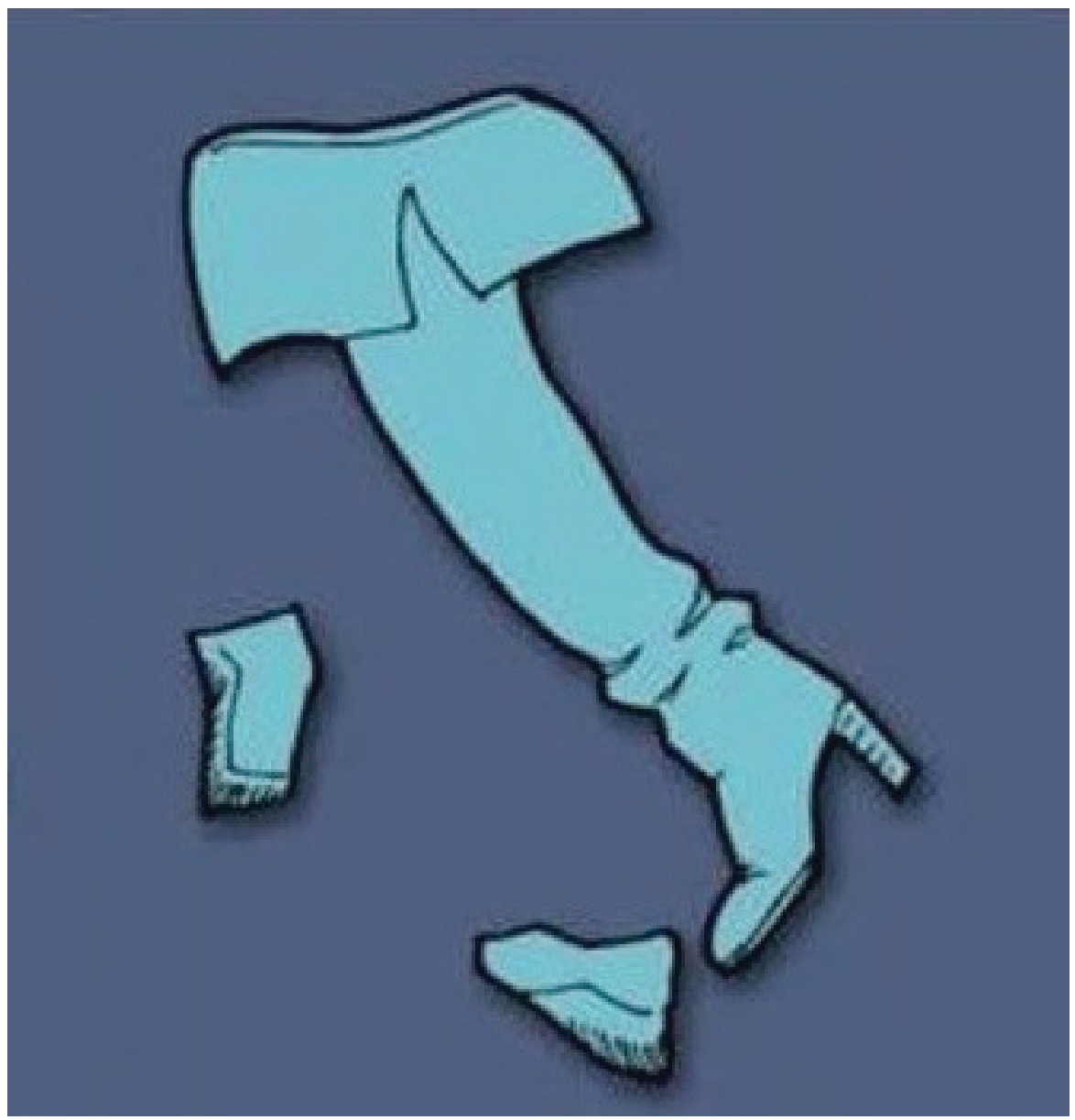

Figure 1.

Italian boot'] . . . implies or introduces or calls to mind a (possible) game of make-believe" (1993: 74) in which we imagine "a boot, while seeing a map of Italy" (1993: 66). This make-believe "is useful for articulating, remembering, and communicating facts about the props - about the geography of Italy" (1993: 41) and is thus prop oriented. We can paraphrase this passage in the following way: in the case of linguistic metaphors, the sentence 'Crotone is on the arch of the Italian boot' is uttered or written down and this triggers a certain prop oriented game of make-believe. It is worth noticing that this is possible only because, thanks to the rules of English, the relevant sentence-token expresses a content, i.e., the proposition that Crotone is on the arch of the Italian boot. Hence, in the case of linguistic metaphors, three key elements are involved: (1) the sentencetoken $p$ (which we will call 'the trigger') expresses (2) the proposition that $p$ (the 
content) which is true according to the fiction $G$ on condition that (3) the realworld fact $G$ (the prop) obtains.

Our proposal can be presented as a generalization of Walton's account. Our main point is that uttering a metaphorical statement might be one way to launch a metaphorical game of make-believe, but it need not be the only one. There might be other triggers beyond sentence tokens. Another way to invite someone to see Italy as a boot is to actually depict Italy as a boot, as in Figure 1. ${ }^{3}$

Remember how things worked in the case of the linguistic metaphor. The trigger in that case was a sentence token, which, in the case of written sentences, is a series of marks on a surface. ${ }^{4}$ Thanks to a certain mechanism - the rules of English - the sentence-token generates a proposition, which is the content of a prop oriented game of make-believe. In the case of the depicted metaphor we also start with marks on a surface; only, this time, instead of a sentence-token we have a picture. The marks on a surface that constitute the picture generate not a proposition, but a depictive content. This depictive content is, in our model, the counterpart of the propositional content generated by the sentence 'Crotone is on the arch of the Italian boot': in so far as it makes sense to compare propositional and non-propositional content, we can say that the picture and the sentence both 'represent' Italy as a boot. 5 The depictive content of the picture, then, becomes the content of a second game of make-believe we engage in, a prop oriented game, where the prop is the same as in Walton's example: the Italian peninsula, with its peculiar geography. Both in the linguistic and in the pictorial case of prop oriented make-believe we are not interested in the fictional world in which Italy is a boot, but in the real world condition that makes it pretenseworthy that Italy is a boot, i.e., that Italy has a certain geography.

In the linguistic case, the proposition expressed by the sentence token is determined by the rules of English. How is depictive content generated? A way to answer this question consists in following Walton's view (1973; 1990), according to which the role played by the rules of English in the linguistic case is played in the pictorial case by a game of make of make believe. Various forms of representation are based on make-believe, Walton argues, and this includes pictorial representations. Pictures, Walton argues, can be "regard[ed] . . as props in games of make-believe" (1973: 300) where one imagines oneself seeing certain scenes in the picture-world so that, for instance, "The colors and shapes on the surface

3. Our claim is consistent with the account of visual metaphors provided by Noël Carroll (2003).

4. We focus on the case where the sentence is written down rather than uttered just to stress the analogy with the depictive case. Nothing important hinges on that.

5. The point of comparing depictive and propositional content is just to understand that they play similar roles in our model, not to put forward an account of the relation between propositional and depictive content. 
of [Brueghel's] Haymaking make it the case that *the peasants are working hard* $(\mathrm{MB})$ " and that "I *look at peasants* (MB)" (Walton 1973: 300, 302). In the case of the depicted metaphor, then, the marks and colors on a pictorial surface are triggers of a prop oriented make-believe game (the usual one in which Italy is the prop), but they work as triggers because they generate a pictorial content, and they generate such content by being the props in a content oriented game of make-believe: the one that generates the content that I look at Italy, which is a boot with Crotone on its arch.

In what follows, we shall partly depart from Walton's view on depiction, dropping the idea that the visual experience of the subject is part of the content of the pictorial game of make-believe. This, as we shall see, allows us to keep our model as simple as possible. Even the choice of using Walton's make-believe theory to explain how pictorial content is generated is not essential to our account. Any mechanism for the generation of pictorial content would do. The central idea we wish to borrow from Walton is exclusively his account of prop oriented make-believe. ${ }^{6}$

Let us now introduce our proposal with the following diagram (Figure 2):

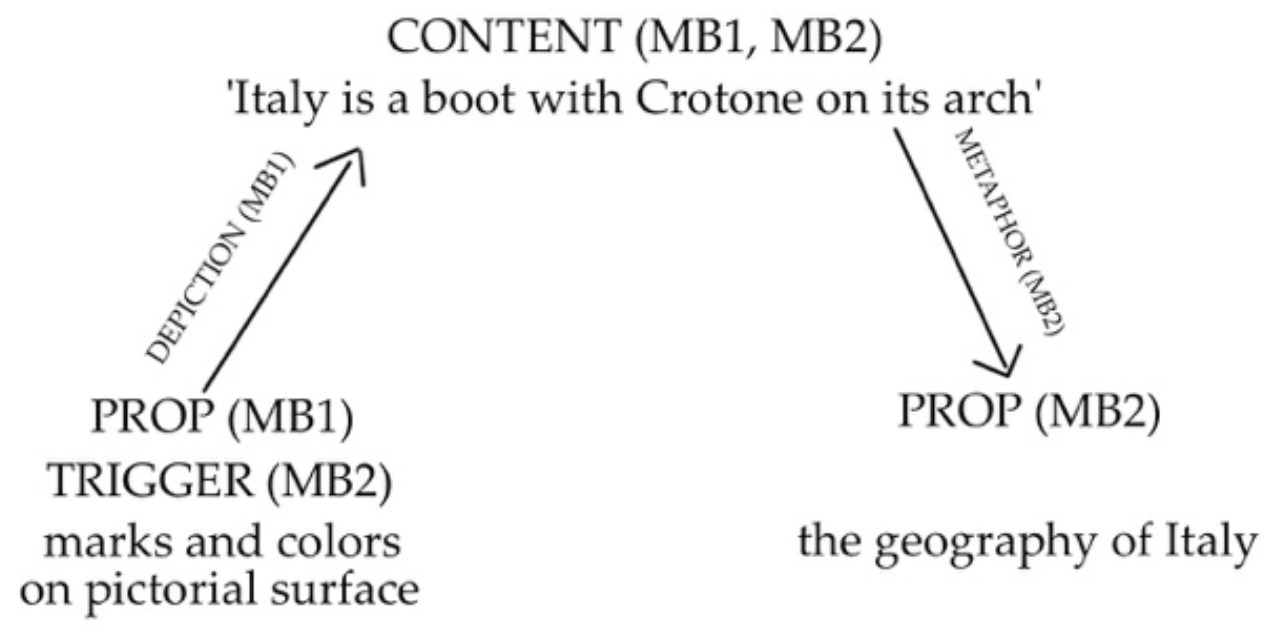

Figure 2.

The first arrow from the left indicates how the picture generates its depictive content: namely, through the mechanism of pictorial representation, which involves, in Walton's account, a content oriented game of make-believe (MB1, also

6. Thanks to a referee from this journal for helping us to clarify this point. 
labeled 'depiction', given that $\mathrm{MB} 1$ is the mechanism generating depictive content). This content is what we are to imagine to be the case: that Italy is a boot and Crotone is on the arch of the Italian boot. The props of the game are the marks and colors on the pictorial surface. When looking at the picture, however, we don't merely pretend that Italy is a boot with Crotone on its arch, i.e., we don't merely play the content oriented game of make-believe. We also engage in a prop oriented game of make-believe (which we call 'metaphor') in which it is fictionally true that Crotone is on the arch of the Italian boot if and only if Crotone has a certain location in the real world (MB2). The prop oriented game is triggered by the marks and colors depicting Italy as a boot. The direction of this second, prop oriented game is indicated by the second arrow. The Italian geography (which includes the real world location of Crotone) is the prop in this second game of make-believe, and the real world location of Crotone is the information conveyed by the metaphorical picture. So we have two games of make-believe: depiction and metaphor; the prop of the depiction are certain configurations of marks and colors on a two-dimensional surface (a picture) and its content is that Italy is a boot and Crotone is on the arch of the Italian boot; the prop of the metaphor is the Italian peninsula and its content is that Italy is a boot and that Crotone is on the arch of the Italian boot. So metaphor and depiction share the same content. 7 They both require us to imagine the same things, but for different reasons: the depiction depicts Italy in a certain way, while the metaphor asks us to pretend Italy is that way on condition that some facts about Italy's geography really obtain.

\section{3.}

In the previous section we have argued that depicted metaphors work like linguistic metaphors. In what follows we will argue that certain caricatures are a kind of depicted metaphors. Caricatures, like metaphors-we submit-engage us in games of prop oriented make-believe. More precisely, as we shall explain, we believe that certain caricatures work like metaphors, while other caricatures work like hyperboles, and that caricatures of both kinds engage us in games of prop oriented make-believe.

7. Our choice to depart from Walton's view on depiction made it possible for us to claim that the contents of the two games of make-believe are identical (see the discussion of this point in Section 2 above). As a referee from this journal pointed out, in order to stick to Walton's proposal it should instead be argued that the contents of the two games of make-believe involved in the metaphorical depiction of Italy as a boot are not the same, although they are systematically related: the content of the content oriented game of make-believe is that the subject is having a visual experience of Italy as a boot with Crotone on its arch, while the content of the prop oriented game of make-believe is that Italy is a boot with Crotone on its arch. 
Suppose that we look at a picture of a strange monkey, that looks a lot like a monkey (it has the feet, legs, arms, hands of a monkey, as well as its ears and snout), but also looks like a human being, since it is wearing a suit and has peculiarly human forehead and hair (see Figure 3, a caricature by Steve Bell). If we know what G.W. Bush looks like, we should be able to see that the creature's eyes, forehead, and hair resemble his eyes, forehead, and hair and, if we follow our simplified version of Walton's view, we can say that by means of looking at the picture we engage in a content oriented game of pictorial make-believe whose content is that G.W. Bush is a monkey. The prop of this game (MB1) are the marks and colors on the surface of the picture, and the content of the game is 'G.W. Bush is a monkey'.

Suppose the picture appears in an illustrated book for children where, simply for the sake of storytelling and without any intention of poking fun at Bush, it is told that Bush has become a monkey. In this case, to understand how the image works, all we need to do is engage in the content oriented game of make-

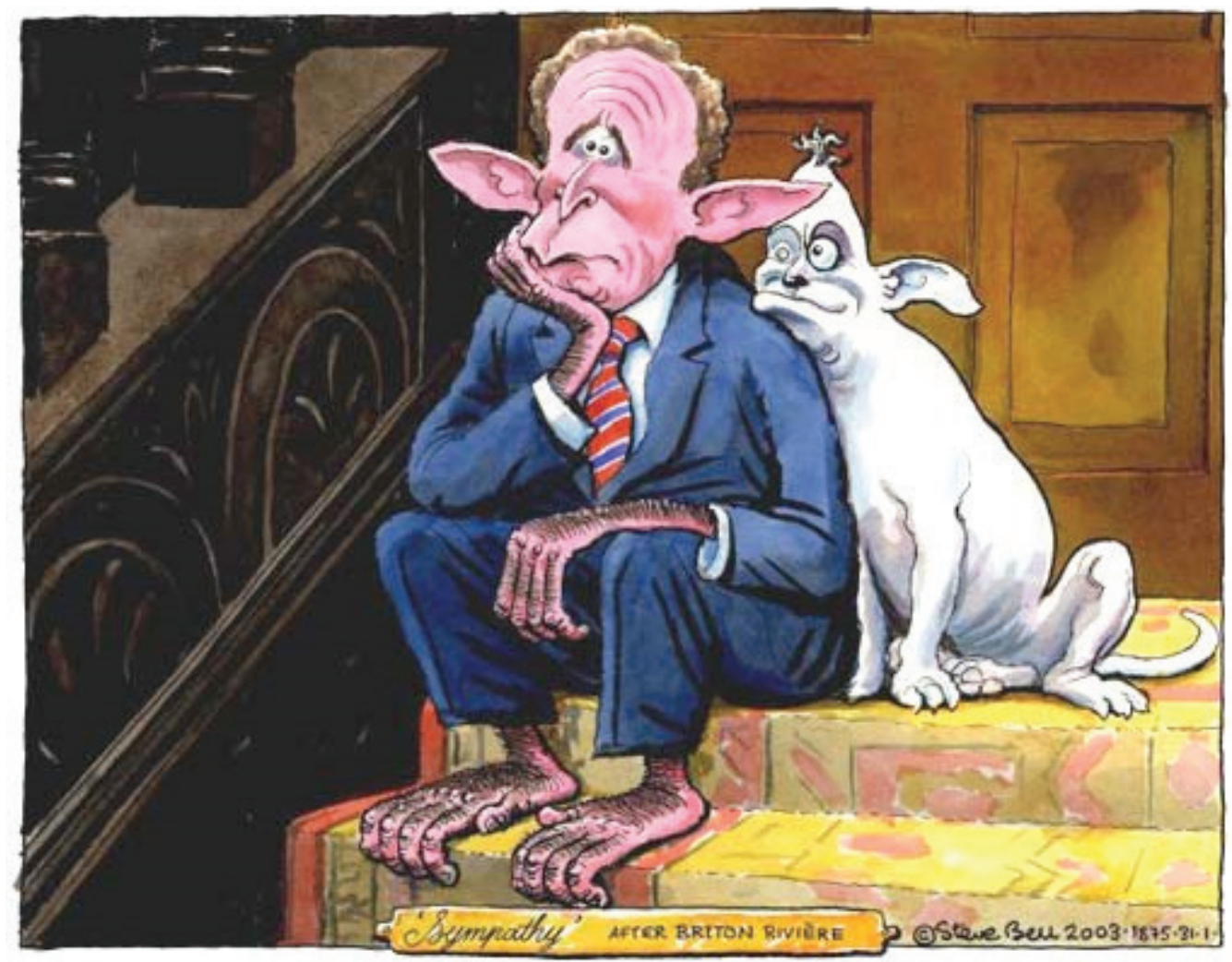

Figure 3. A caricature of George W. Bush by Steve Bell. Copyright @ Steve Bell 2003 - All Rights Reserved. 
believe just described. What we are interested in while engaging in this game of make-believe is the depictive content of the picture, i.e., that Bush is a monkey.

Suppose now that the same picture is used as a caricature of G.W. Bush. Our thesis is that, in order to use the image as a caricature of G.W. Bush, not only we engage in a game of make-believe that makes it true in the fictional world that G.W. Bush is a monkey ( $\mathrm{MB} 1)$, but we also engage in a prop oriented game of make-believe (MB2), where certain intellectual or behavioral properties that can be attributed to Bush, the referent of the depiction, are the props (the properties at issue are those that make him appear monkey-like, such as being slow, dull, and clumsy). The prop oriented game (MB2) is triggered by the marks and colors on the surface of the picture; its content, i.e., 'G. W. Bush is a monkey', is the same content of the content oriented game we engage in while recognizing that the picture depicts Bush ( $\mathrm{MB} 1)$, but its props are different than that of the content oriented game: in MB2 the props are certain of Bush's intellectual or behavioral properties, whereas in $\mathrm{MB} 1$ the props are marks and colors on the pictorial surface (the trigger of the make-believe game in $\mathrm{MB}_{2}$ ). While engaging in $\mathrm{MB} 2$, we are interested in how imagining Bush as a monkey can be used to point out certain of his intellectual or behavioral properties, which are typically attributed to monkeys. Given that our focus is on the props, we are confronted with a case of prop oriented make-believe. Let us see how our general schema applies to Bush's caricature (Figure 4).

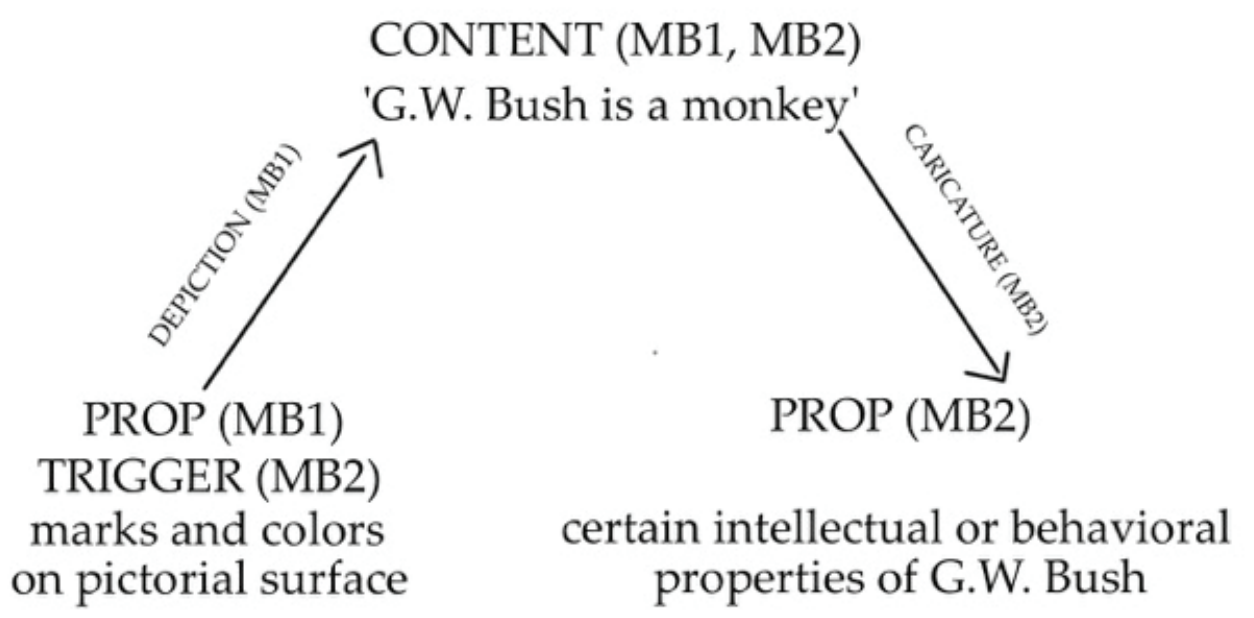

Figure 4 .

As illustrated in Figure 4, we have a content oriented game of make-believe (MB1) where the marks and colors on the pictorial surface are the props and 
the content is that Bush is a monkey. The props of MBI are also the triggers of a second game of make-believe (MB2), which has certain of G.W. Bush's intellectual or behavioral properties as props and 'G.W. Bush is a monkey' as content. $\mathrm{MB} 2$ is prop oriented, in that we are interested in focusing on certain properties of G.W. Bush while engaging in it. The prop oriented game allows us to understand that the picture is not just the picture of a monkey-like G.W. Bush, but it is a caricature of G.W. Bush as a monkey. ${ }^{8}$

Stephen Yablo (1998; see also Walton 1993) explains how certain metaphors are 'procedurally essential': instead of being uttered by a speaker who has a definite message to convey, they require one to look for the appropriate prop oriented game of make-believe that allows one to understand the meaning of the metaphorical talk. For instance, while interpreting 'Juliet is the sun' one is confronted with a certain content (of a game of make-believe) and required to ponder what is the prop associated to such content in the game. Once singled out the prop which figures in the appropriate game of make-believe-and there might be several different games and therefore several different props that work in this case, e.g., Juliet's beauty, or her vital importance for Romeo-one can understand the meaning of the metaphorical talk, because such talk is about the prop. "Someone who utters $S$ in a metaphorical vein is recommending the project of (i) looking for games in which $S$ is a promising move, and (ii) accepting the propositions that are S's inverse images in those games under the modes of presentation that they provide" (Yablo 1998: 253).

It seems to us that caricatures work like Yablo's procedurally essential metaphors. Consider again the G.W. Bush caricature (Figure 3). While facing such caricature we engage in a game of make-believe which generates the fictional truth 'G.W. Bush is a monkey', but we are also prompted to engage in a second game of make-believe, which is prop oriented and leads us to acknowledge that its props are certain of G.W. Bush's intellectual or behavioral properties. While looking at the picture of G.W. Bush as a monkey (MB1), we ponder about which of G.W. Bush's properties are props in the second game of make-believe (MB2), where we pretend that people with certain intellectual or behavioral properties are monkeys. The principles of generation of $\mathrm{MB}_{2}$ are all the instances of the schema: $x$ has certain properties iff according to the fiction $x$ is a monkey. The principles of generation of $\mathrm{MB} 2$ include as an instance: it is fictionally true

8. There is an affinity between our account and the recognitional account of caricature sketched by Catharine Abell and Gregory Currie (1999): they claim that we are able to "conclude that ... [a] caricature depicts person X not on the basis of any X-identifying feature of the picture, but on the basis of some X-identifying feature of what the picture depicts" (1999: 439). This is akin to our claim that we are capable of understanding that a certain picture is the caricature of a certain subject not in virtue of the content of the game of make-believe we engage in while looking at such caricature $\left(\mathrm{MB}_{1}\right)$, but rather in virtue of the prop oriented game of make-believe (MB2) we engage in while looking at it (i.e., in virtue of features of the caricatured subject). 
in $\mathrm{MB} 2$ that Bush is a monkey if and only if Bush has certain intellectual or behavioral properties. Representing Bush as a monkey, i.e., pretending that he is a monkey, then, conveys to players engaged in $\mathrm{MB} 2$ the message that Bush has certain intellectual or behavioral properties (e.g., being slow, dull, and clumsy): this message is what we call 'the real content' of the caricature.

When Figure 3 is used as a caricature of G.W. Bush, what is fictionally true (i.e., that G.W. Bush is a monkey) is used to point out certain properties of G.W. Bush. The picture introduces us to a game of make-believe in which we are to imagine of people with such intellectual or behavioral properties that they are monkeys. By doing so, we focus on the properties of G.W. Bush that make it fictionally true that he is a monkey. Although the picture is not visually accurate, it is metaphorically accurate: the literal content of the metaphor (that Bush is a monkey) is not true, but the real content of the metaphor (that Bush has certain monkey-like intellectual or behavioral properties) might be. 9

\section{4 .}

One could think that caricatures, in general, are visually inaccurate, but convey correct information about non-visual aspects of the subjects they represent. As we shall argue, however, hyperbole-like caricatures are capable of conveying correct information about the visual aspects of the subjects they represent, albeit in a peculiar way. Hyperbolic talk resembles certain caricatures in that they both

9. Our view is compatible with the account of the 'epistemic abuse and misuse of pictorial caricature' recently offered by Christy MagUidhir (2013). MagUidhir's proposal can be summed up as follows. He considers four claims: (a) editorial cartoons are capable of informing like editorial writing; (b) pictorial caricatures can be revelatory about the nature of their subjects; (c) caricatures have persuasive power; (d) a caricature has a "unique ability to exploit the powerful and pervasive cognitive biases of its audience" (2013: 137). He argues that (c) is true, but its truth is grounded in (d), rather than being grounded in (b), from which it follows that (a) is false. Moreover, he generalizes the claim about (a) to "any medium substantially employing caricature ... in service to some epistemic uptake [arguing that any such medium] is thereby to that extent an epistemically defective medium" (2013: 138). None of this impinges on the truth of (b) (see MagUidhir 2013: 145). With reference to MagUidhir's account, our proposal can be said to revolve uniquely around claim (b). We are interested in explaining how pictorial caricatures can be revelatory about the nature of their subjects and we argue that this is because they engage us in prop oriented games of make-believe. This fact about caricature is compatible with their capability of engaging us, at the same time, in content oriented games of make-believe as well. In the fictional games prompted by caricatures, the content of the games is not epistemically reliable, for the reasons explained by MagUidhir - but the reason why we are able, in the first place, to understand that certain pictures are caricatures, rather than, for instance, non-intentional misrepresentations, or lifelike pictures, is that we engage not only in content oriented, but also in prop oriented games of make-believe while looking at them. 
involve an exaggeration of the truth - and exaggerating the truth might be a way to convey correct information. ${ }^{10}$

We will first argue that hyperbolic talk, just like figurative talk, can be understood as involving engagement in a form of prop oriented make-believe. We will also point out that just as our previous example of a caricature can be understood as a depicted metaphor, other caricatures can be understood as depicted hyperboles. Following our idea to treat the linguistic and the pictorial case alike, we will then submit that hyperbolic caricatures, just like their linguistic counterparts, can be understood as involving prop oriented make-believe.

Walton's (1993) proposal is to understand the utterance of some metaphorical statements as moves in a prop oriented make-believe game. We submit that also some hyperbolic statements can be understood as moves in prop oriented make-believe games of a certain kind: "games where the truth of a part licenses us in pretending the whole" (Yablo 2014: 199). "Games of this type" Yablo explains "have players in a broad sense exaggerating - saying more than they mean-so let's call them hyperbolic" (2014: 199). These games employ a "booster device [B]" (2014: 191); in a hyperbolic game " $X$ makes it fictional that $Y$ just if $Y$ follows from $X \& B^{\prime \prime}$ (2014: 191). Here is an example of how a hyperbolic game might work. The game G might have the following booster device B: if something moves very fast for ordinary standards, it moves at the speed of light. B makes it fictional that John moves at the speed of light on condition that John moves very fast. The booster device might be interpreted as a generation principle:

$(G)$ 'x moves at the speed of light' is fictionally true iff $x$ moves very fast.

This example shows that hyperbolic games have the form of games of makebelieve: they specify what is fictional as a function of how the world is. What is assertable when speaking hyperbolically coincides with what is fictional according to a hyperbolic game like G. When uttering the hyperbolic statement 'John moves at the speed of light' as a move in the hyperbolic game G our focus is on the real-world situation, i.e., the prop, that makes it fictional that John moves at the speed of light, i.e., John's ability to move really fast. Understanding the hyperbolic statement 'John moves at the speed of light' involves engaging in a prop oriented game of make-believe which is triggered by such sentence, whose content is the proposition that John moves at the speed of light, and whose prop is John's ability to move really fast.

Just as some caricatures can be understood as depicted metaphors, other car-

10. For a recent account of hyperbole and meiosis as figures of speech see Kendall Walton (2015). 
icatures can be understood as depicted hyperboles. If we combine the idea that some caricatures can be understood as depicted hyperboles with the idea that hyperbolic statements resemble metaphors in that they involve prop oriented make-believe, we can understand depicted hyperboles as involving some form of prop oriented make-believe.

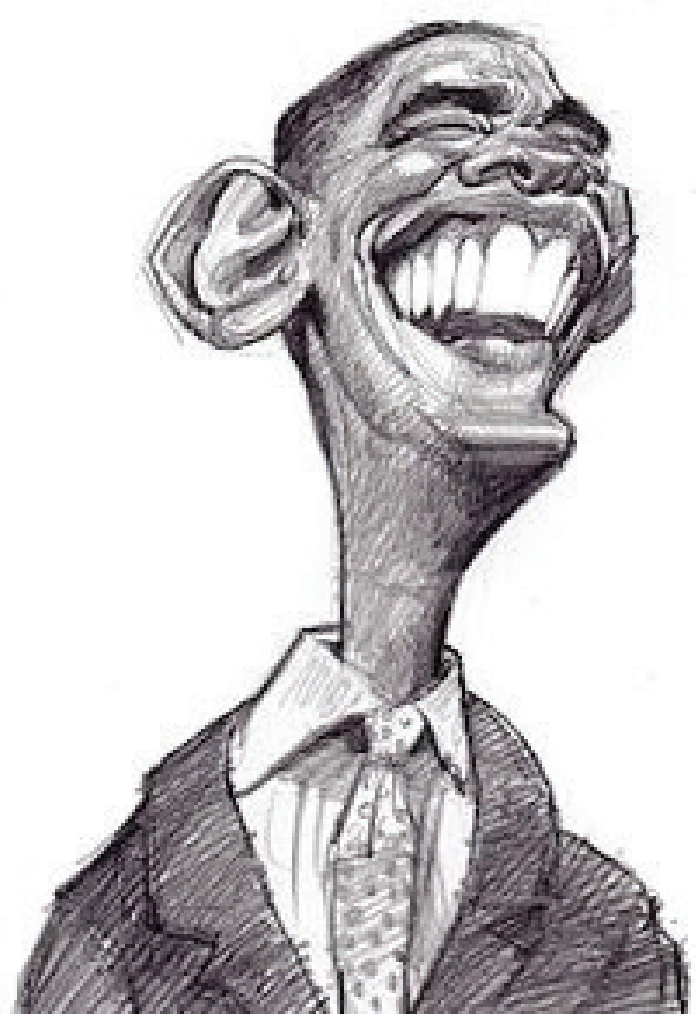

Figure 5. A caricature of Barack Obama by Jan Op De Beek. Copyright Jan Op De Beek.

To portray somebody as having a giant mouth and enormous ears (see Figure 5, a caricature by Jan Op De Beek) might be a way to point out a real aspect of such person's face-among others (note that Figure 5 also conveys the metaphor that Obama has a big mouth). Let us apply once more our schema to analyze how this image works (Figure 6).

Here we have a content oriented game of make-believe (MBI) where the marks and colors on the pictorial surface are the props and the fictional truth generated is 'Obama has abnormal ears and mouth' (this is the content of the game). The marks and colors on the pictorial surface also trigger a second game of make-believe (MB2), where the prop is Obama's face, and the content is the 


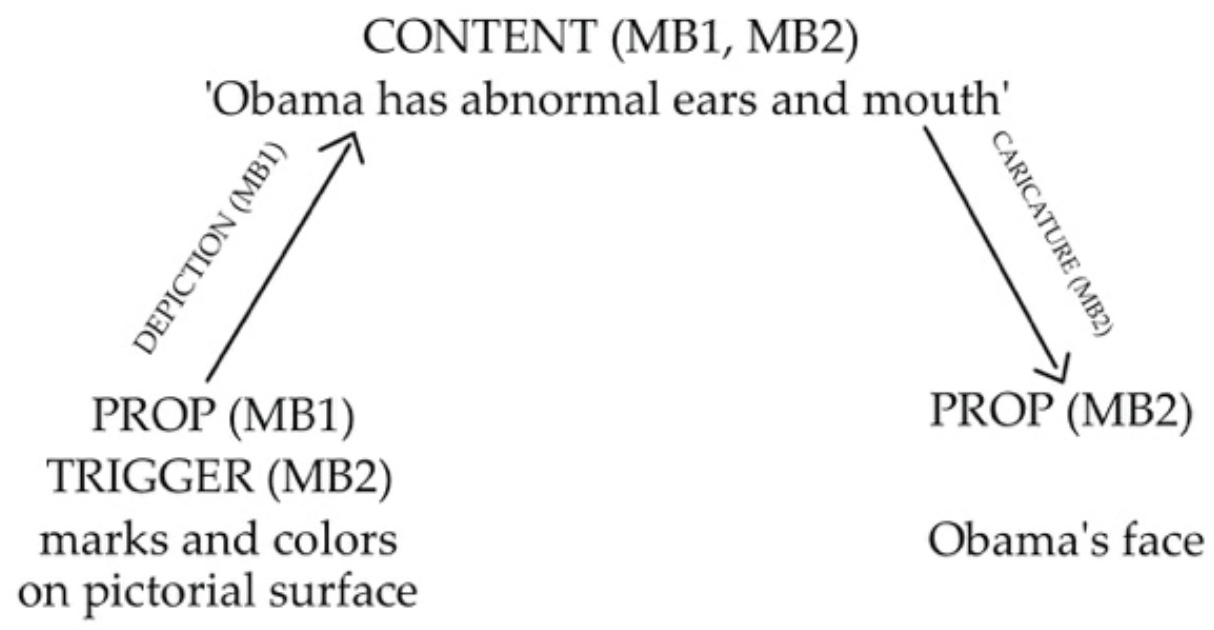

Figure 6.

same as in the first game: 'Obama has abnormal ears and mouth'. By means of engaging in $\mathrm{MB}_{2}$ we grasp the fact that Figure 5 is not a mere misrepresentation of Obama, but rather a caricature of Obama and a quite vivid representation of him, in a sense.

\section{$5 \cdot$}

To conclude, the idea of considering caricatures as a case of prop oriented makebelieve seems a promising way to account for their representational power, just as Walton's idea of linking metaphor and prop oriented make-believe provides an elegant explanation of the expressive utility of figurative language. A caricature invites us to ponder what aspects of the subject it portrays are caricatured by it and, as a consequence, it focuses our attention on such aspects of the caricatured subject. In the jargon of the make-believe theory, as we argued, this means that caricatures engage us in games of prop oriented make-believe, where we seek to understand what exactly is the prop associated with the content of the game of make-believe at issue. A corollary of this way of looking at caricatures is that caricatures can be effective representations, either of non-visual aspects of depicted characters, or of visual aspects of them, or of both. The metaphorical picture of Italy as a boot conveys accurate information about the location of Crotone; the caricature of G.W. Bush as a monkey conveys accurate information about certain intellectual or behavioral properties of G.W. Bush and the carica- 
ture of Obama with huge ears and mouth conveys the accurate information that he has rather big ears and a rather large mouth. The accurate information is not conveyed by means of depictions that are faithful to the visual appearance of Italy, G.W. Bush, or Obama, but by means of misrepresentations that work in a peculiar way, i.e., as caricatures (visual metaphors or hyperboles).

\section{Acknowledgments}

Elisa Caldarola is the main author of this paper. Matteo Plebani wrote Section 1 , the introduction and Section 4 were jointly written, and Elisa Caldarola wrote the rest of the paper.

The authors would like to thank Kendall Walton, Patrick Maynard, the audience at the 2015 European Society for Aesthetics Conference in Dublin, and two anonymous referees from this journal for their comments. The authors would like to thank Steve Bell and Jan Op De Beeck for granting permission to reproduce their caricatures.

Elisa Caldarola acknowledges financial support of her work by the University of Padova through the project: Disagreement. A Pluralist Approach (2015-2017). Matteo Plebani acknowledges financial support of his work by the Spanish Ministry of Economy and Competitiveness and FEDER through the project: The Explanatory Function of Abstract Objects: Their Nature and Cognoscibility, FFI201341415-P.

\section{References}

Abell, Catharine and Gregory Currie (1999). Internal and External Pictures. Philosophical Psychology, 12(4), 429-445. http://dx.doi.org/10.1080/095150899105675

Carroll, Noël (2003). Visual Metaphor. In Noël Carroll (Ed.), Beyond Aesthetics: Philosophical Essays (347-368). Cambridge University Press.

Goodman, Nelson (1968). Languages of Art. Bobbs-Merrill.

Liggins, David (2014). Abstract Expressionism and the Communication Problem. British Journal for the Philosophy of Science, 65(3), 599-620. http://dx.doi.org/10.1093/bjps/ axt012

MagUidhir, Christy (2013). Epistemic Misuse and Abuse of Pictorial Caricature. American Philosophical Quarterly, 50(2), 137-151.

Ross, Stephanie (1974). Caricature. The Monist, 58(2), 285-293. http://dx.doi.org/10.5840/ monist197458221

Walton, Kendall (1973). Pictures and Make-Believe. Philosophical Review, 82(3), 283-319. http://dx.doi.org/10.2307/2183897

Walton, Kendall (1990). Mimesis as Make-Believe: On the Foundations of the Representational Arts. Harvard University Press. 
Walton, Kendall (1993). Metaphor and Prop Oriented Make-Believe. European Journal of Philosophy, I(1), 39-57. http://dx.doi.org/10.1111/j.1468-0378.1993.tb00023.x

Walton, Kendall (2015). Meiosis, Hyperbole, Irony. Philosophical Studies. Advance online publication. http://dx.doi.org/10.1007/s11098-015-0546-6

Yablo, Stephen (1998). Does Ontology Rest on a Mistake? Aristotelian Society Supplementary Volume, 72(1), 229-283. http://dx.doi.org/10.1111/1467-8349.00044

Yablo, Stephen (2005). The Myth of the Seven. In Mark Eli Kalderon (Ed.), Fictionalism in Metaphysics (88-115). Clarendon Press.

Yablo, Stephen (2014). Aboutness. Princeton University Press. http://dx.doi.org/10.1353/ book.36513 